\title{
Numerical simulation of one-dimensional mixed flow with air/water interaction
}

\author{
F. Kerger ${ }^{1,2}$, S. Erpicum ${ }^{1}$, P. Archambeau ${ }^{1}$, B. J. Dewals ${ }^{1,2}$ \\ \& M. Pirotton ${ }^{1}$ \\ ${ }^{1}$ Laboratory of Hydrology, Applied Hydrodynamics and Hydraulic \\ Constructions (HACH), Liège University, Belgium \\ ${ }^{2}$ Belgian Fund for Scientific Research F.R.S-FNRS, Belgium
}

\begin{abstract}
An original one-dimensional unified numerical model dealing with aerated mixed flow, characterized by a simultaneous occurrence of free-surface and pressurized flow, is derived and applied to the case of a gallery. The mathematical model is based on a new integration of the Homogeneous Equilibrium Model (HEM) over the cross section of a free-surface flow and consists of a simple set of equations analogous to the Saint-Venant equations. In addition, both free-surface and pressurized flows are mathematically modeled by means of the free-surface set of equations (Preissmann slot model). The original concept of the negative Preissmann slot is proposed to simulate sub-atmospheric pressure. This model is shown to be particularly well suited for the simulation of bubbly and intermittent flows.
\end{abstract}

Keywords: hydraulics, Preissmann slot, homogeneous equilibrium model.

\section{Introduction}

Mixed flows, characterized by the simultaneous occurrence of free-surface and pressurized flows, are frequently encountered in river networks, sewer systems, storm-water storage pipes, flushing galleries, bottom outlets,... As a matter of fact, some hydraulic structures are designed to combine free-surface and pressurized sections (e.g. water intakes). In addition, dynamic pipe filling bores may occur in hydraulic structures designed only for conveying free-surface flow under an extreme water inflow or upon starting a pump. During such a transition, highly transient phenomena appear and may cause structural damages to the 
system [1], generate geysers through vertical shafts [2], engender flooding,... What is more, air/water interactions may arise, particularly at the transition bore [3], and thoroughly alter the flow regime and its characteristics. On account of the range of applications affected by mixed flows, a good prediction of mixed flow features is an industrial necessity. Numerical simulation of mixed flow remains, however, challenging for two main reasons. Dissimilarity in the pressure term arises between the classical sets of equations describing free-surface and pressurized flows. Air/water interaction has to be taken into account through a two-phase flow model.

Different mathematical approaches to describe mixed flows have been developed to date. Firstly, the so-called shock-tracking approach consists of solving separately free-surface and pressurized flows through different sets of equations [4, 5]. Secondly, the Rigid Water Column Approach [6] treats each phase (air/water) separately on the basis of a specific set of equations. The latter approach succeeds in simulating complex configurations of the transition. However, using this method for practical application is not possible because of the complexity and specificity of the algorithm. Thirdly, the so-called shockcapturing approach is a family of methods that computes pressurized and free-surface flows by using a single set of equations [7-9]. In this paper, a shock-capturing approach is used, based on the widespread model of the Preissmann slot [7]. Free-surface flow and pressurized flow are in this way equally solved through a free surface set of equations. An original concept developed by the authors, the negative Preissmann slot, extends the Preissmann slot model to simulate sub-atmospheric pressurized flows.

Computing air-water interaction requires using a two-phase flow model. On the one hand, to the authors' knowledge, no mixed flow model takes into account the effect of entrained air in the water flow. Only the air phase pressurization is usually modeled, as in the Rigid Water Column [6] and in the shock-capturing model of Vasconcelos et al. [8]. On the other hand, the usual multiphase flow investigations focus mainly on fully pressurized flow in small diameter pipes for chemical and mechanical engineering applications. There have been only a few attempts, often based on a transport equation [10], to simulate air entrainment in large hydraulic structures. Consequently, the current research aims at applying the classical model for multiphase flow to civil engineering applications. In this paper, an Homogeneous Equilibrium Model (HEM) coupled with the Preissmann slot model is derived by using the time and area averaging methods proposed by Ishii and Hibiki [11].

These developments have been carefully implemented in the one-dimensional module of the software package WOLF. WOLF is finite volume flow simulation modeling system developed within the Laboratory of Hydrology, Applied Hydrodynamics and Hydraulic Constructions (HACH) of the University of Liege.

Application to this new model to the case of flows in a gallery is presented in this paper. Experimental results from a physical model build in the Laboratory of Structures Hydraulics of the University of Liege are used for comparison with numerical results. 


\section{Mathematical model}

\subsection{Homogeneous equilibrium model for free-surface flow}

Homogenous flow theory provides the simplest technique for analyzing multiphase flows. Using suitable averaged properties, the fluid is treated as a pseudo-fluid that obeys the usual equations of a single-component flow. Under the assumption of equality between air and water properties, one obtains the Homogeneous Equilibrium Model (HEM) as demonstrated by Ishii and Hibiki [11]. This assumption is particularly suited for dispersed bubbly flow. The model is commonly used for the simulation of heat exchangers $[12,13]$, two-phase flow in ducts $[14], \ldots$

\subsubsection{D Time-averaged governing equations}

HEM may be considered as a simplification of the Drift Flux Model [11] if the drift or diffusion of mass is negligible regarding the continuity equation for the gas phase. Thus, HEM 3D model is derived through the time averaging of the Local Instant Formulation for multiphase flow, the introduction of suitable mixture variables and the assumption of equilibrium between phases. For further details, we refer the interested reader to the classical book of Ishii and Hibiki [11]. The resulting equations write:

$$
\left\{\begin{array}{cc}
\frac{\partial \rho_{\mathrm{m}}}{\partial \mathrm{t}}+\nabla\left(\rho_{\mathrm{m}} \mathbf{v}_{\mathrm{m}}\right)=0 \quad & \text { (continuity equation) } \\
\frac{\partial \alpha_{\mathrm{g}}}{\partial \mathrm{t}}+\nabla\left(\alpha_{\mathrm{g}} \mathbf{v}_{\mathrm{m}}\right)=\Gamma_{\mathrm{g}} & \text { (diffusion equation) } \\
\frac{\partial \rho_{\mathrm{m}} \mathbf{v}_{\mathrm{m}}}{\partial \mathrm{t}}+\nabla\left(\rho_{\mathrm{m}} \mathbf{v}_{\mathrm{m}} \mathbf{v}_{\mathrm{m}}\right)=-\nabla \mathrm{p}_{\mathrm{m}}+\nabla\left(\tau_{\mathrm{m}}+\tau^{\mathrm{T}}\right)+\rho_{\mathrm{m}} \mathbf{g}+\mathbf{M}_{\mathrm{m}} & \text { (momentum equation) }
\end{array}\right.
$$

where $\rho_{\mathrm{m}}\left[\mathrm{kg} / \mathrm{m}^{3}\right]$ is the mixture density, $\mathbf{v}_{\mathrm{m}}\left[\mathrm{ms}^{-1}\right]$ is the mixture velocity vector (under the assumption of velocity equilibrium, $\mathbf{v}_{\mathrm{m}}=\mathbf{v}_{\text {water }}=\mathbf{v}_{\text {air }}$ ), $\alpha_{\mathrm{g}}[-]$ is the air void fraction, $\Gamma_{\mathrm{g}}\left[\mathrm{s}^{-1}\right]$ the phase change volume generation, $\mathrm{p}_{\mathrm{m}}\left[\mathrm{Nm}^{-2}\right]$ is the mixture pressure, $\tau_{\mathrm{m}}\left[\mathrm{Nm}^{-2}\right]$ and $\tau^{\mathrm{T}}\left[\mathrm{Nm}^{-2}\right]$ are the viscous and turbulent stress tensors, $\mathrm{g}\left[\mathrm{ms}^{-2}\right]$ is the gravity and $\mathbf{M}_{\mathrm{m}}\left[\mathrm{kgs}^{-2} \mathrm{~m}^{-2}\right]$ is the interfacial momentum source.

Closure of eqn (1) requires the definition of the mixture variables and a constitutive equation. Air and water are supposed to be incompressible Newtonian fluid, and the mixture properties write then:

$$
\begin{aligned}
& \rho_{\mathrm{m}}=\alpha_{\mathrm{g}} \rho_{\mathrm{g}}+\left(1-\alpha_{\mathrm{g}}\right) \rho_{\mathrm{w}} \cong\left(1-\alpha_{\mathrm{g}}\right) \rho_{\mathrm{w}} \\
& \tau_{\mathrm{m}}=\left[\alpha_{\mathrm{g}} \mu_{\mathrm{g}}+\left(1-\alpha_{\mathrm{g}}\right) \mu_{\mathrm{w}}\right]\left(\nabla . \mathbf{v}+(\nabla \cdot \mathbf{v})^{\mathrm{T}}\right)
\end{aligned}
$$

At this point, no assumption is needed for the constitutive equations of the turbulent stress $\tau^{\mathrm{T}}$, the phase change volume generation $\Gamma_{\mathrm{g}}$, the pressure distribution $\mathrm{p}_{\mathrm{m}}$ and the mixture momentum source $\mathbf{M}_{\mathrm{m}}$. 


\subsubsection{Area average of three-dimensional homogeneous equilibrium model}

1D HEM equations are obtained by area-averaging eqns (1) and (2) over the cross section of the flow. The originality of the following development is to consider a free-surface flow. It is indeed shown in section 3 how we use the freesurface set of equations to simulate pressurized flow as well. The whole process of integration is beyond the scope of this paper. It is performed by analogy to the integration of the Saint-Venant equation for pure water flow, as exposed in [15]. The flow is assumed to flow in the $x$-direction. Successive integration over the flow width (y-abscissa) and the flow depth (z-abscissa) results in a set of conservative hyperbolic partial differential equations that describe the flow below a free-surface. A non-dimensional analysis of eqn (1) leads to the following expression for the mechanical constitutive equation:

$$
\mathrm{p}(\mathrm{x}, \mathrm{z}, \mathrm{t})=\int_{-\mathrm{h}_{\mathrm{b}}}^{\mathrm{z}}-\rho_{\mathrm{m}} \mathrm{g} \cos \theta \mathrm{dz}=(1-\bar{\alpha}) \rho_{\mathrm{w}} \mathrm{g}\left(\mathrm{z}-\mathrm{h}_{\mathrm{b}}\right)
$$

where $h_{b}$ is the distance between the $\mathrm{z}$-abscissa and the bottom of the flow area. Eqn (3) simply states that the pressure distribution over the flow area is hydrostatic. 1D HEM for free-surface flow writes at the end of the day:

$$
\frac{\partial}{\partial \mathrm{t}}\left(\begin{array}{c}
= \\
\alpha \Omega \\
(1-\bar{\alpha}) \Omega \\
(1-\bar{\alpha}) \overline{\mathrm{u}}_{\mathrm{m}} \Omega
\end{array}\right)+\frac{\partial}{\partial \mathrm{x}}\left(\begin{array}{c}
==\overline{\mathrm{u}}_{\mathrm{m}} \Omega \\
(1-\bar{\alpha})=\overline{\mathrm{u}}_{\mathrm{m}} \Omega \\
(1-\bar{\alpha})=2 \\
\overline{\mathrm{u}}_{\mathrm{m}} \Omega
\end{array}\right)=\left(\begin{array}{c}
\overline{\overline{\Gamma_{\mathrm{g}}}} \\
0 \\
\mathrm{~g}(1-\bar{\alpha}) \Omega\left(\frac{\partial \mathrm{Z}}{\partial \mathrm{x}}-\mathrm{S}_{\mathrm{F}}\right)-\mathrm{gp}_{\mathrm{w}} \frac{\partial \bar{\alpha}}{\partial \mathrm{x}}
\end{array}\right)
$$

where $\mathrm{p}_{\mathrm{w}}=\int_{-\mathrm{h}_{\mathrm{b}}}^{\mathrm{h}_{\mathrm{s}}}\left(\mathrm{h}_{\mathrm{s}}-\mathrm{z}\right) 1(\mathrm{z}) \mathrm{dz}, \Omega\left[\mathrm{m}^{2}\right]$ is the flow cross-section area, $\mathrm{u}_{\mathrm{m}}$ is the flow velocity, $Z[\mathrm{~m}]$ is the free surface elevation, $S_{F}[-]$ is the friction slope (resulting from the integration of the viscous, turbulent shear stress and the interfacial momentum source). The area-average of a given function $\mathrm{f}$ is defined as:

$$
\overline{\bar{f}}(x, t) \triangleq \frac{1}{\Omega} \int_{-h_{b}}^{h_{f}} \int_{-l_{d}}^{l_{g}} f(x, y, z, t) d y d z
$$

As pointed in [13], two-phase friction slope $\mathrm{S}_{\mathrm{F}}$ may be computed using the Darcy-Weisbach relation. The Colebrook relation for the friction factor still holds if a suitable "virtual viscosity" for the mixture is computed:

$$
\begin{aligned}
& S_{F}=\frac{f u_{m}^{2}}{2 D_{h}} \text { with } \sqrt{\frac{1}{f}}=-2 \log \left(\frac{k}{3.7 D_{h}}+\frac{2.51}{\operatorname{Re} \sqrt{f}}\right) \\
& \operatorname{Re}=\frac{(1-\alpha) \rho_{w} u_{m} D_{h}}{\mu_{m}} \text { with } \mu_{m}=(1+\alpha) \mu_{w}
\end{aligned}
$$

with $D_{h}[\mathrm{~m}]$ the hydraulic diameter of the cross-section, $\mathrm{k}[\mathrm{m}]$ is the roughness height, $\operatorname{Re}[-]$ the Reynolds Number and $\mu_{\mathrm{w}}\left[\mathrm{kgm}^{-1} \mathrm{~s}^{-1}\right]$ the dynamic viscosity. 
To close the partial differential system given by eqn (4), we still need to give an expression for the phase change volume generation $\Gamma_{\mathrm{g}}$. Literature is abundant for empirical relations. To keep the generality of the model, a very fundamental relation given in [10] for air entrainment in free-surface flow is used:

$$
\overline{\bar{\Gamma}}_{g}=-m \Gamma\left(\alpha-\alpha_{e q}\right)
$$

where $\Gamma$ and $\alpha_{\mathrm{g}}$ are constants calibrated with experimental results. The onset of air entrainment is controlled by the parameter $\mathrm{m}=1$ or $\mathrm{m}=0$.

Discretization of eqns (4)-(7) is performed by means of a finite volume scheme with an original flux vector splitting [16]. Time discretization is based on an explicit Runge-Kutta scheme to enhance the convergence in steady state applications.

\subsection{Preissmann slot model}

Pressurized flows are commonly described through the Allievi equations [17]. According to the Preissmann slot model [7], pressurized flow can be equally calculated through the free-surface equations by adding a conceptual slot at the top of a closed pipe (Figure 1b). When the water elevation is above the pipe crown, it provides a conceptual free-surface flow, of which the gravity wavespeed is given by $c=\sqrt{g \Omega / T_{s}}$ ( $\mathrm{T}_{\mathrm{s}}$ is the slot width). Strictly speaking, the pressure wave celerity of a flow in a full pipe, referred by $\mathrm{a}[\mathrm{m} / \mathrm{s}]$, depends on the properties of the fluid, the pipe, and its means of support. In first approximation, its value is not dependant of the pressure value and may be computed on the basis of solid mechanics relations [17]. It is then easy to choose a slot width $T_{s}$ which equalizes the gravity wavespeed $\mathrm{c}$ to the water hammer wavespeed a:

$$
\mathrm{T}_{\mathrm{s}} \triangleq \frac{\mathrm{g} \Omega}{\mathrm{a}^{2}} \quad \text { with } \quad \mathrm{a}^{2} \triangleq \mathrm{A} \frac{\mathrm{dp}}{\mathrm{d}(\rho \mathrm{A})}
$$

From a hydraulic point of view, all the relevant information is summarized in the relation linking the water height and the flow area $(\mathrm{H}-\mathrm{A})$. A specific relation corresponds to each geometry of the cross section (Figure 1a). Adding the Preissmann slot leads to linearly extend the relation beyond the pipe crown head. In order to simulate pressurized flows with a piezometric head below the pipe crown, the authors propose a new concept, called negative Preissmann slot. It consists in extending the Preissmann straight line for water height below the pipe crown (Figure 1c). Two values of the flow area correspond to each water level below the pipe crown: one for the free surface flow and one for the pressurized flow. The choice between the two relations is done according to the local aeration conditions.

For steady flow applications, the choice of the slot width may be arbitrary. On the one hand, the wave celerity does not affect the steady state of a flow. On the other hand, explicit numerical schemes are characterized by a time step $\Delta \mathrm{t}$ that is limited by a CFL condition of the form

$$
\mathrm{NbC} \leq 1 \quad \text { with } \quad \mathrm{NbC} \triangleq \max \left(\left|\mathrm{u}_{\mathrm{m}}\right|+\mathrm{c}\right) * \frac{\Delta \mathrm{x}}{\Delta \mathrm{t}}
$$




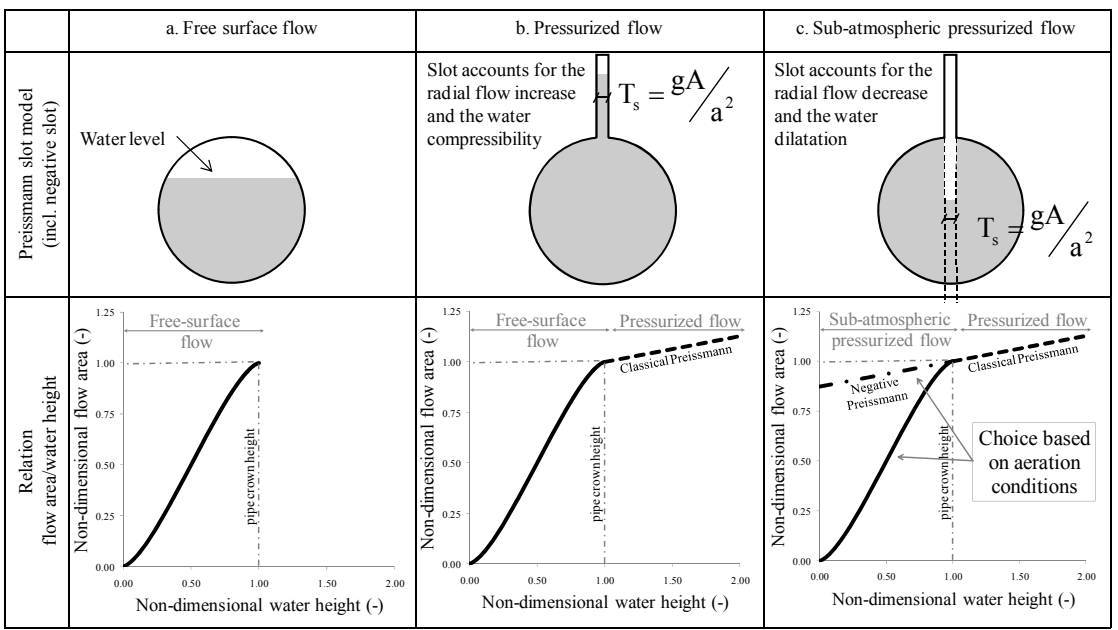

Figure 1: $\quad$ The Preissmann slot method under different flow conditions.
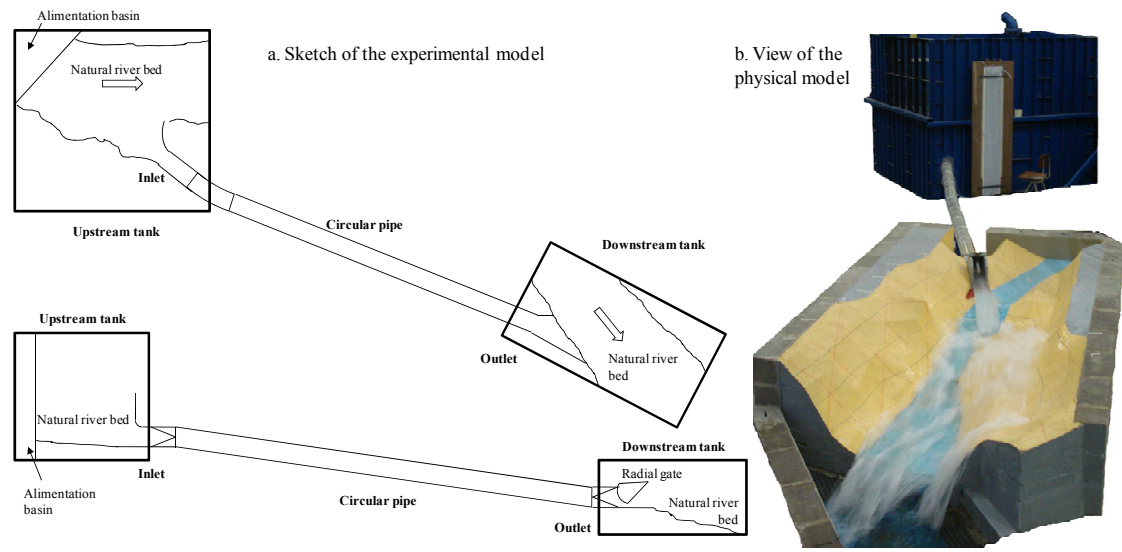

Figure 2: Description of the experimental setup.

It seems then reasonable to impose a wider slot than the width calculated with eqn (4) in order to decrease the computation time.

\section{Steady flow application}

This section outlines the application of the one-dimensional HEM solver for simulating stationary mixed flows taking place in a gallery. Numerical results are compared with experimental results provided by experimental investigations carried out in the Laboratory of Structures Hydraulics (HACH) of the University of Liege. The model (figure 2) includes a Plexiglas circular pipe linking two tanks. Topography of the upstream and downstream tanks has been built 
regarding realistic in-situ natural conditions. The gallery inlet and outlet structures are also represented. Experimental apparatus, measurement systems and results are described in details in [18].

\subsection{Experimental investigations}

Investigations focus mainly on stationary flows and aims at determining the flow discharge through the gallery as a function of the upstream pressure head. Strong air/water interactions may alter the flow behavior. In particular, the flow discharge through the gallery is strongly influenced by air/water interaction, and consequently depends of the aeration rate as well.

Various two-phase flow patterns are observed according to the flow discharge through the gallery. Figure 4 shows the experimental relation between the flow discharge and the upstream pressure head (zero level is set at the upstream reservoir bottom level). The curve defines 5 areas corresponding to the 5 flow patterns (Figure 3) traditionally mentioned in the literature [13]:

1. A pure water fully free surface flow or smooth stratified flow.

2. A wavy stratified flow.

3. An intermittent flow that includes slug flow as well as plug flow.

4. A bubbly flow.

5. A pure water pressurized flow.

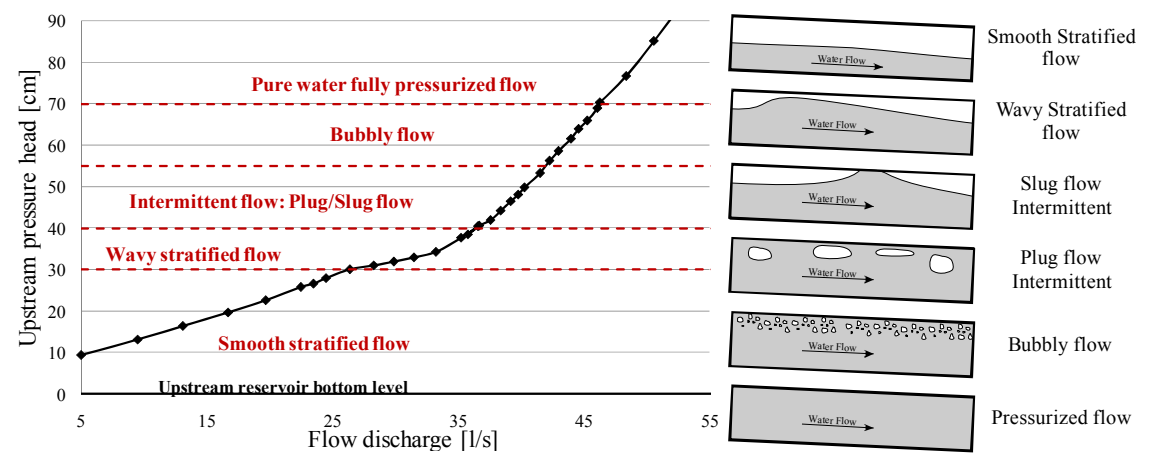

Figure 3: $\quad$ Experimental relation (upstream pressure head-flow discharge).

\subsection{Pure water simulation}

Simulations are performed under the assumption of a pure water flow (void fraction is equal to zero). They use a discretization step $\Delta x=3.33 \mathrm{~cm}$, a CFL number limited to 0.5 and a roughness height $\mathrm{k}=2.10^{-5} \mathrm{~m}$. The flow discharge varies between $51 / \mathrm{s}$ and 551/s. Results provide new insight into the flow behavior. A first head/discharge relation (dotted line in figure 4) is computed with the HEM model and assuming a free surface in each mesh if the water height is below the pipe crown (air phase above the free surface is at atmospheric pressure). The second head/discharge relation (continuous line) is computed by activating the negative Preissmann slot (sub-atmospheric pressurized flow). 


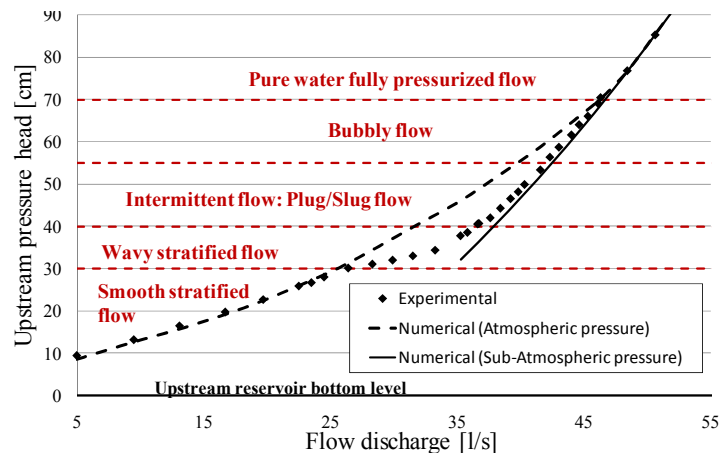

Figure 4: Computed flow discharge relation for pure water simulations.
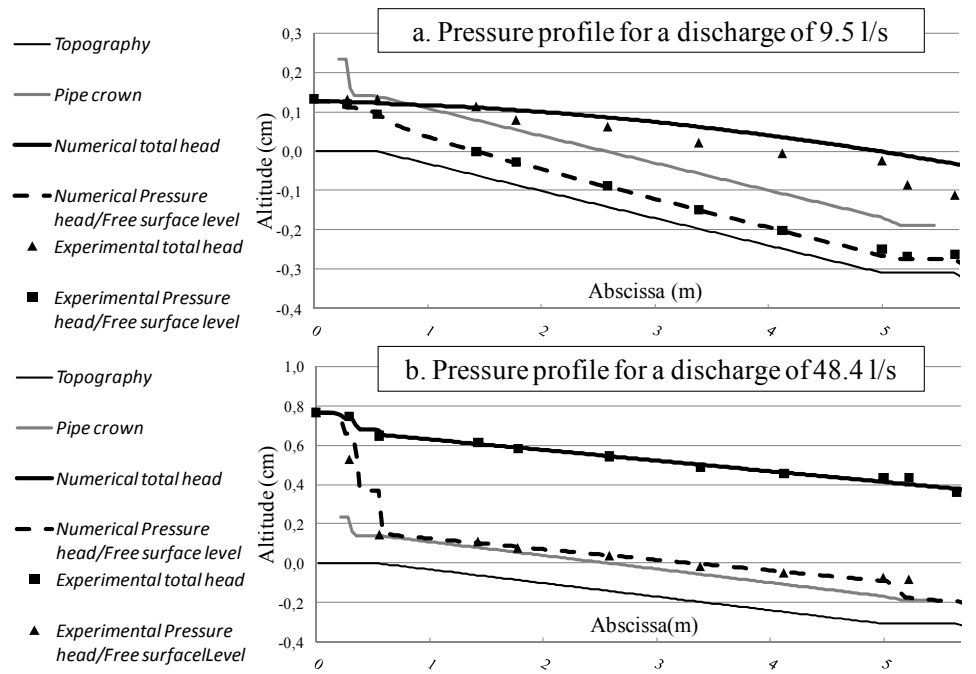

Figure 5: Computed total head and pressure head distribution for a smooth stratified flow and a pressurized flow.

Numerical results are in good accordance with experimental data for smooth stratified flows and fully pressurized flows. Bubbly and intermittent flows show a similar behavior two the sub-atmospheric pressurized flows. A periodic instability between to unstable steady flow regimes occurs in the area of wavy stratified flows. The instability induces large period (10s to $60 \mathrm{~s})$ oscillation of the water level in the upstream reservoir. The amplitude of the oscillation reaches $2 \mathrm{~cm}$. Consequently, very large pressure oscillations (up to $4 \mathrm{~cm}$ ) are observed in the gallery. For further details over this regime, we refer the interested reader to the paper of Erpicum et al. [18].

Experimental and numerical data for the distribution of the total head and the pressure head (water level for free surface flow) along the gallery length are given in figure 5 for a smooth stratified flow (discharge of 9.51/s) and a fully 
pressurized flow (discharge of 48.41/s). In the latter case, results are in full agreement. In the former case, a slight discrepancy is observed in the total head curve. It results from the effect of the air phase flowing above the free surface that is not taken into account in the computation.
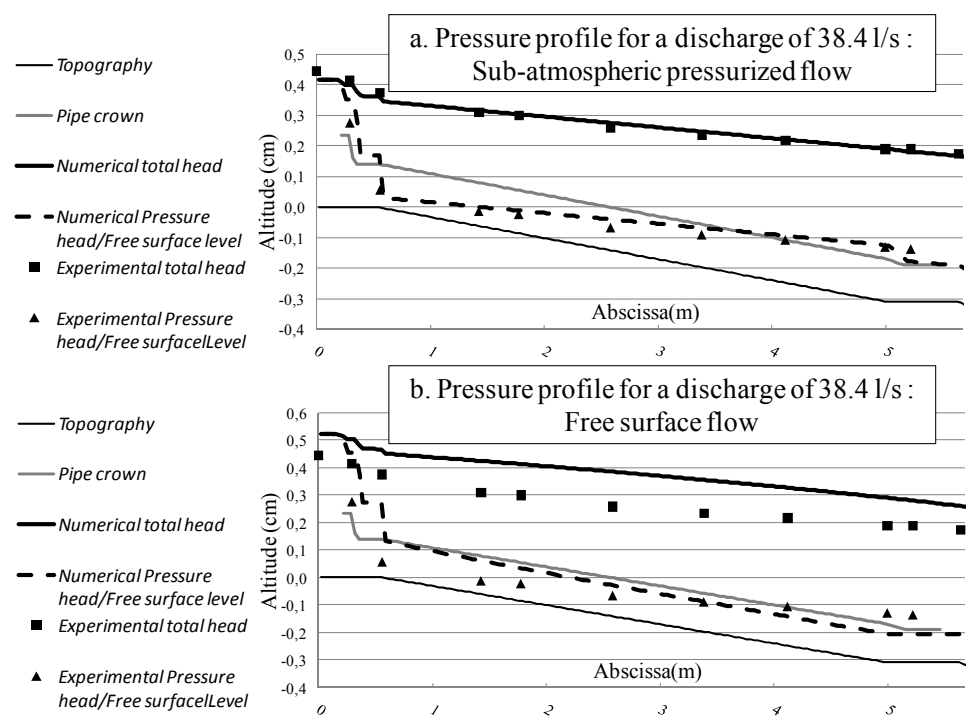

Figure 6: Computed total head and pressure head distribution for an intermittent flow sub-atmospheric pressurized flow and free-surface flow computation.

A comparison of the results given by the computation for an intermittent flow of 38.41/s discharge is shown in figure 6. Pressure distribution along the gallery is computed in figure $6 \mathrm{~b}$ under the assumption of a free surface flow. Large discrepancies of the results are observed. The upstream pressure head is overestimated. In figure 6a, activation of the negative Preissmann slot gives the curve corresponding to a pressurized flow. We consequently identify a large area of sub-atmospheric pressure in the upstream part of the pipe. Results are now in better accordance and it has been concluded that the aeration rate of the pipe is not sufficient to induce the apparition of a free surface flow. However, some differences still remain.

\subsection{Air-water mixture simulation}

Application of the Homogeneous Equilibrium Model enables to overcome the results discrepancy observed in section 3.2 for bubbly and intermittent flows (figure 4 and 6). The effect of the entrained air on the water flow is accurately computed by using the eqn (7) for the phase change volume generation $\Gamma_{\mathrm{g}}$. The parameter $\Gamma$ is set at 25 and $\alpha_{\mathrm{g}}$ is calibrated according to the flow pattern observed. For bubbly flows, as bubbles arise from the air dissolved in water, 
equilibrium void fraction is chosen between $0.5 \%$ and $2 \%$. For intermittent flows, an additional air supply is provided through a vertical vortex appearing at the water intake. Equilibrium void fraction is then chosen between $2 \%$ and $4.5 \%$.

Figure 7 a shows a comparison between experimental and numerical data for the relation between the flow discharge through the gallery and the upstream pressure head. Taking into account air/water interaction in the computation obviously gives more accurate results for bubbly and intermittent flows. The void fraction relation corresponding to this new relation is given in Figure $7 \mathrm{~b}$.

A comparison between experimental data and numerical results computed with the HEM scheme is drawn on figure 8 . Computation is performed with a flow discharge of $38.41 / \mathrm{s}$ and a void fraction of $4.5 \%$. Results are in full agreement.
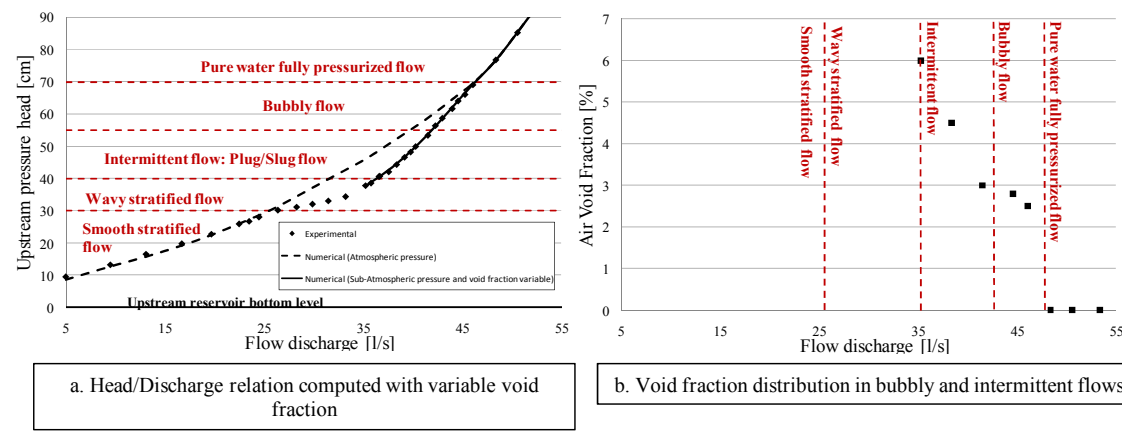

b. Void fraction distribution in bubbly and intermittent flows

Figure 7: Results of air-water mixture simulation.
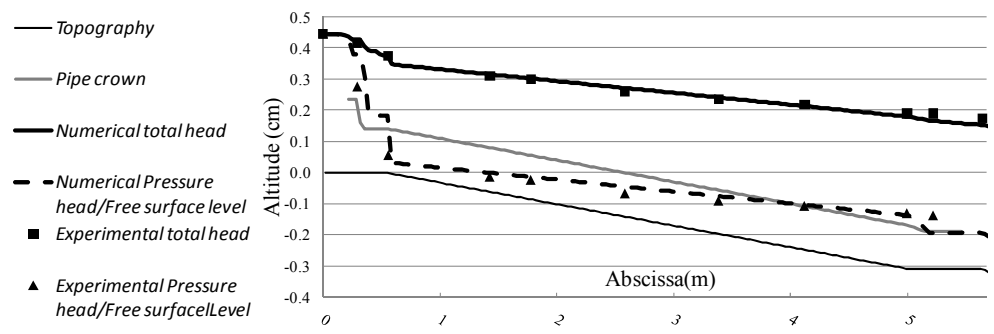

Figure 8: $\quad$ Computed total head and pressure head distribution for a bubbly (flow discharge of $38.4 \mathrm{l} / \mathrm{s}$ and void fraction of $4.5 \%$ ).

\section{Conclusion}

The original mathematical model derived in this paper is a first step towards a completely unified model for the simulation of highly transient mixed flow in multi-scale hydraulic structures. Thanks to the Preissmann slot method, both free-surface and pressurized flow are calculated through the free-surface set of equation by adding a narrow slot at the top of the pressurized sections. In 
addition, an original negative Preissmann slot has been added to simulate subatmospheric pressure. Area-integration of the Homogeneous Equilibrium Model (HEM) over the cross section give a simple set of equations, analogous to the Saint-Venant equations, for analyzing air-water flows. This assumption has been shown to be particularly well-suited for the simulation of bubbly and intermittent flows.

The fundamental concepts introduced in the previous pages pave the way for further research. Experimental research is required to develop appropriate source terms as phase change volume generation and interfacial momentum source. Development of a stratified air/water model would give us insight into wavy stratified flows. All results should be then easily extended to multidimensional problems.

\section{References}

[1] Zhou, F., F.E. Hicks, and P.M. Steffler, Transient Flow in a Rapidly Filling Horizontal Pipe Containing Trapped Air, Journal of Hydraulic Engineering, 128(6): p. 625-634, 2002

[2] Guo, Q. and C. Song, Dropshaft Hydrodynamics under Transient Conditions, Journal of hydraulic Engineering, 117(8): p. 1042-1055, 1991

[3] Vasconcelos, J. and S. Wright, Experimental Investigation of Surges in a Stormwater Storage Tunnel, Journal of hydraulic Engineering, 131(10): p. 853-861, 2005

[4] Cardle, J. and C. Song, Mathematical Modeling of Unsteady Flow in Storm Sewers, International Journal of Engineering Fluid Mechanics, 1(4): p. 495-518, 1988

[5] Politano, M., A.J. Odgaard, and W. Klecan, Numerical Evaluation of Hydraulic Transients in a Combined Sewer Overflow Tunnel System, Journal of Hydraulic Research, 133(10): p. 1103-1110, 2007

[6] Li, J. and A. McCorquodale, Modeling Mixed Flow in Storm Sewers, Journal of hydraulic Engineering, 125(11): p. 1170-1180, 1999

[7] Preissmann, A. Propagation des intumescences dans les canaux et rivieres. in First Congress of the French Association for Computation, Grenoble, France, 1961

[8] Vasconcelos, J., S. Wright, and P.L. Roe, Improved Simulation of Flow Regime Transition in Sewers : The Two-Component Pressure Approach, Journal of Hydraulic Engineering, 132(6): p. 553-562, 2006

[9] Bourdarias, C. and S. Gerbi, A Finite Volume Scheme for a Model Coupling Free Surface and Pressurized Flows in Pipes, Journal of Computational and Applied Mathematics, 209: p. 109-131, 2007

[10] Dewals, B.J., S. Andre, M. Pirotton, and A. Schleiss. Quasi 2D-numerical model of aerated flow over stepped chutes. in 30th IAHR Congress, Greece, 2003

[11] Ishii, M. and T. Hibiki, Thermo-fluid dynamics of two-phase flow. First ed, ed. U. Springer Science: Springer Science, USA. 430, 2006 
[12] Clerc, S., Numerical Simulation of the Homogeneous Equilibrium Model for Two-phase Flows, Journal of Computational Physics, 161: p. 354-375, 2000

[13] Wallis, G.B., One-dimensional Two-phase Flow, ed. M.-H.B. Company. 410, 1969

[14] Guinot, V., Godunov-type Schemes: An introduction for engineers, ed. E. Science. Amsterdam. 480, 2003

[15] Cunge, J.A., F.M. Holly, and A. Verwey, Practical Aspects of Computational River Hydraulics. [Monographs and surveys in water resources engineering], 3. Boston: Pitman Advanced Pub. Program. 1980

[16] Dewals, B.J., S. Erpicum, P. Archambeau, S. Detrembleur, and M. Pirotton, Depth-Integrated Flow Modeling Taking into Account Bottom Curvature, Journal of Hydraulic Research, 44(6): p. 787-795, 2006

[17] Wylie, E.B. and V.L. Streeter, Fluid transients. Première ed, ed. M.-H. Inc., 385,1978

[18] Erpicum, S., F. Kerger, P. Archambeau, B.J. Dewals, and M. Pirotton. Experimental and numerical investigation of mixed flow in the flushing gallery of a dam. in Multiphase Flow New Forest, 2008 